\title{
Pengaruh Kepemimpinan Terhadap Kepuasan Kerja Guru Pada Smpn 1 Banuhampu Kabupaten Agam
}

\author{
Nikmatul Husna \\ Universitas Putra Indonesia YPTK Padang, Indonesia \\ Email: nikmatulhusna11@gmail.com
}

\begin{abstract}
This research was accomplished by Nikmatul Husna, 2014422030, Department of Magister Management, 2014.2, with the title THE INFLUENCE OF LEADERSHIP TOWARD WORK SATISFACTION IN SMPN 1 BANUHAMPU KABUPATEN AGAM.

The purpose of this research is to identify and analyze the influence of leadership toward work satisfaction in SMPN 1 Banuhampu Kabupaten Agam. The population of the research is the teachers in SMPN 1 Banuhampu Kabupaten Agam. Samples taken are 56 respondents by using random sampling technique, which determine samples by taking a sample randomly and use the questionnaire as a tool to collect data. Based on hypothesis in this research, it is assumed that the influence of leadership significantly and positively influence the teachers' work satisfaction in SMPN 1 Banuhampu Kabupaten Agam.

The data analysis methods author used in this research are validity tes, reliability test, variable descriptive analysis test, simple linear regression analysis, $\mathrm{T}$ test and $\mathrm{F}$ test. From analysis that have been done, author found that leadership variable $\left(\mathrm{X}_{1}\right)$ is significantly and positively influence the satisfaction of teachers' work, this is proven by the significant probability value of leadership is resulted in 0,000 which is smaller than 0,05 . From $\mathrm{F}$ test, it can be concluded that regression model can be use to predict the leadership which have significantly and positively influence toward teachers' work satisfaction by the significant probability value is resulted in 0,000 which is smaller than 0,05 .
\end{abstract}

Keywords: Leadership , Teachers' Work Satisfaction

\section{Pendahuluan}

Perkembangan sebuah organisasi sangat ditentukan oleh seberapa besar asset yang dimiliki oleh organisasi tersebut. Manajemen sumber daya yang baik mengharuskan kepala sekolah menemukan dan memberi cara terbaik dalam mengelola guru agar tercapai tujuan organisasi serta meningkatkan kepuasan kerja dari seorang guru dalam bekerja. Menurut Strauss dan Sayless dalam Pandji Anoraga (2007:242) kepuasan kerja penting untuk aktualisasi diri. Pegawai yang tidak memperoleh kepuasan kerja tidak akan pernah mencapai kematangan psikologis dan akan mengakibatkan frustasi dan stress. Jadi apabila seorang guru itu puas maka ia akan bekerja lebih bersemangat, tentunya kepuasan seseorang tidak terlepas dari bagaimana kepemimpinan kepala sekolah didalamnya agar tujuan organisasi tersebut tercapai.

Kepemimpinan menurut Robbins (2003:280) merupakan kemampuan untuk mempengaruhi suatu kelompok kearah tercapainya suatu tujuan. Kemampuan pemimpin dalam menggerakkan dan memberdayakan para guru akan berpengaruh terhadap kepuasan kerja guru tersebut. Apabila seorang kepala sekolah sudah bisa menjadi seorang pemimpin yang baik tentu kepuasan kerja guru akan tercapai.

Dari hasil pengamatan sementara yang penulis amati pada Sekolah Menengah Pertama Negeri (SMPN) 1 Banuhampu Kabupaten Agam terlihat berbagai kekurangan seperti kepemimpinan yang terjadi disini semena-mena, dimana pimpinan mengambil keputusan secara sepihak tanpa adanya kesepakatan bersama, kurang ada keterbukaan, bersifat acuh tak acuh, kurang memberikan nasehat, masukan serta mengayomi para guru agar tercapai tujuan yang telah ditetapkan, sehingga sering terjadinya ketidakharmonisan antara komponen sekolah. Apabila hal ini terus dibiarkan maka kepuasan kerja guru tidak dapat dipenuhi. Apabila kepuasan kerja guru turun, maka guru bekerja tersebut kurang bersemangat baik mengajar, tidak bertanggung jawab terhadap tugas dan tanggung 
jawab yang diberikan kepadanya, kurang disiplin. Sehingga akan berdampak pada keberhasilan hasil belajar siwa dan tercapainya tujuan sebuah organisasi. Seperti yang terlihat pada table dibawah ini:

Tabel 1

Daftar Lulusan SMPN 1 Banuhampu Kabupaten Agam Yang diTerima Di SMAN Tahun 20122014

\begin{tabular}{|c|c|c|c|c|c|c|}
\hline \multirow{2}{*}{ No } & Tahun & \multicolumn{6}{|c|}{ Jumlah Kelulusan dan Kelanjutan Studi } \\
\cline { 3 - 7 } & $\begin{array}{c}\text { Ajara } \\
\text { n }\end{array}$ & $\begin{array}{c}\text { Jumlah } \\
\text { Lulus }\end{array}$ & $\begin{array}{c}\text { Diterima di } \\
\text { SMA N }\end{array}$ & $\begin{array}{c}\text { Persentase } \\
\text { \% }\end{array}$ & $\begin{array}{c}\text { Tidak Diterima di } \\
\text { SMA N }\end{array}$ & $\begin{array}{c}\text { Persentas } \\
\text { e \% }\end{array}$ \\
\hline 1. & 2012 & 216 & 177 & 81,94 & 39 & 18,06 \\
\hline 2. & 2013 & 187 & 158 & 84,50 & 29 & 15,5 \\
\hline 3 & 2014 & 193 & 145 & 75,12 & 48 & 24,88 \\
\hline
\end{tabular}

Sumber: SMPN 1 Banuhampu Kabupaten Agam

Berdasarkan data diatas, terlihat pada tahun 2012 siswa yang lulus sebanyak 216 yang diterima di SMAN sebanyak 177 (81,94\%), sedangkan siswa yang tidak diterima di SMAN adalah sebanyak 39 orang $(18,06 \%)$. Pada tahun 2013 terlihat bahwa jumlah siswa yang lulus adalah sebanyak 187 orang, dan yang diterima di SMAN adalah sebanyak $158(84,50 \%)$ selebihnya tidak diterima di SMAN yaitu sebanyak 29 orang $(15,5 \%)$. Sedangkan pada tahun 2014 siswa yang diterima di SMAN mengalami penurunan yakni sebanyak 145 orang $(75,12 \%)$, yang tidak diterima sebanyak 48 orang $(24,88)$. Berarti lulusan SMPN 1 Banuhampu Kabupaten Agam yang diterima di SMAN 1 masih jauh dari yang diharapkan. Hal ini secara tidak langsung merupakan gambaran dari proses belajar mengajar. Dimana apabila guru puas, tentulah hasil lulusannya juga banyak yang diterima di SMAN 1 .

Ini yang melatar belakangi penulis untuk meneliti lebih jauh mengenai "Pengaruh Kepemimpinan Terhadap Kepuasan Kerja Guru Pada SMPN 1 Banuhampu Kabupaten Agam".

\section{Metodologi Penelitian}

Penilitian ini penulis lakukan pada SMPN 1 Banuhampu Kabupaten Agam. jenis penelitian yang dilakukan adalah penelitian deskriptif dengan menggunakan pendekatan kuantitatif yaitu mencoba untuk menggambarkan, menentukan dan menafsirkan suatu objek dalam bentuk konsep. Populasi dalam penelitian ini adalah para guru yang ada di SMPN 1 Banuhampu Kabupaten Agam. Sampel yang diambil sebanyak 56 responden dengan menggunakan teknik random sampling, yaitu teknik penentuan sampel dengan mengambil sampel secara acak dan menggunakan kuesioner sebagai alat pengumpul data. Teknik yang dipakai dalam pengumpulan data yaitu melalui riset perpustakaan, penelitian lapangan, browsing internet, metode dokumentasi dan penyebaran angket. Definisi operasional yang dimaksud adalah untuk menjelaskan makna variabel yang sedang diteliti (Riduwan,2015), difinisi operasional yang akan dijelaskan dalam penelitian ini dilihat dari variabel independen $\left(\mathrm{X}_{1}\right)=$ Kepemimpinan dengan indikator pengukuran menurut James M.Kouzes dan Barry Z.Posner (2004) dalam Riduwan (2015:210) yaitu: 1)menantang proses, 2)memprakarsai visi bersama, 3)memungkinkan orang lain untuk bertindak, 4)menjadi model, 5)membangkitkan semangat dan variabel dependen $(\mathrm{Y})=$ Kepuasan kerja Guru, dengan indikator pengukuran menurut Veithzal Rivai (2009:860) yaitu:1) pekerjaan, 2)bayaran/upah, 3)rekan kerja, 4)promosi, 5)supervisor. Adapun metode analisis data yang penulis gunakan dalam melakukan penelitian ini adalah dengan menggunakan uji validitas dan uji reliabilitas, analisis deskriptif variable, analisis regresi linier sederhana, uji T dan uji F.

\section{Hasil Dan Pembahasan}

\section{Hasil Uji Validitas Dan Reliabilitas}

Dari hasil pengujian instrumen dalam penelitian ini menunjukkan bahwa seluruh item pernyataan pada variabel kepemimpinan dan kepuasan kerja guru dinyatakan valid, karena koefisien korelasi dengan butir skor total lebih besar dari 0,222 ( $\mathrm{r}$ hitung >0,222). Hal ini merujuk kepada pendapat Imam Ghozali (2013) yang mengatakan bahwa alat untuk mengukur validitas adalah Korelasi Product Moment dari Pearson. Dengan ketentuan:

$$
\text { Hasil } r_{\text {hitung }}>r_{\text {tabel }}(0,222)=\text { valid }
$$


Hasil $r_{\text {hitung }}<r_{\text {tabel }}(0,222)=$ tidak valid

Rumus untuk mencari $r_{\text {tabel }}$ :

$$
\begin{aligned}
\mathrm{Df} & =\mathrm{n}-2 \\
\mathrm{Df} & =56-2 \\
& =54
\end{aligned}
$$

$r_{\text {tabel }}=0,222$

Maka dapat disimpulkan bahwa didalam penelitian ini didapat $r$ hitungnya lebih besar dari pada $r$ tabel dan dinyatakan semua instrumen valid dan dapat dilanjutkan kepengujian selanjutnya.

Sementara dari hasil pengujian instrumen reliabilitas variabel kepemimpinan dan kepuasan kerja guru menunjukkan bahwa nilai Cronbach's Alpha untuk setiap variabel lebih besar dari 0,6, Hal ini menandakan bahwa semua variabel penelitian memiliki kuesioner yang handal atau sangat reliabel. Dengan demikian dapat disimpulkan bahwa kuesioner yang digunakan untuk mengumpulkan data penelitian sangat handal sehingga memenuhi syarat untuk pengumpulan data.

\section{Hasil Uji Deskriftif Variabel Penelitian}

Berdasarkan data yang diperoleh dari lapangan yang disesuaikan dengan fokus pernyataan penelitian, dalam bab ini akan disajikan data secara deskriptif,

\section{a. Hasil Uji Distribusi Frekuensi Variabel Kepuasan Kerja Guru}

\begin{tabular}{|c|c|c|c|c|}
\hline No & Pernyataan & $\begin{array}{l}\text { Rata- } \\
\text { rata }\end{array}$ & TCR & Ket \\
\hline 1 & Pekerjaan yang saya lakukan sangat menarik & 4.12 & 82,4 & Baik \\
\hline 2 & Pekerjaan yang saya lakukan sangat memuaskan & 3.98 & 79,6 & Baik \\
\hline 3 & $\begin{array}{l}\text { Saya memiliki kreativitas tersendiri agar pekerjaan saya } \\
\text { cepat selesai }\end{array}$ & 4,21 & 84,2 & Baik \\
\hline 4 & $\begin{array}{l}\text { Saya merasa tertantang dengan pekerjaan yang diberikan } \\
\text { kepada saya }\end{array}$ & 4.34 & 86,8 & Baik \\
\hline 5 & $\begin{array}{l}\text { Saya merasa gaji yang diberikan pimpinan sudah cukup } \\
\text { untuk memenuhi kebutuhan normal saya }\end{array}$ & 4.20 & 84 & Baik \\
\hline 6 & $\begin{array}{l}\text { Pimpinan memberikan gaji lebih apabila hasil kerja saya } \\
\text { bagus }\end{array}$ & 4,16 & 83,2 & Baik \\
\hline 7 & Saya bekerja dengan rekan kerja yang bertanggung jawab & 4,32 & 86,4 & Baik \\
\hline 8 & $\begin{array}{l}\text { Saya merasa senang dengan sikap saling menghormati } \\
\text { didalam organisasi }\end{array}$ & 4,21 & 84,2 & Baik \\
\hline 9 & $\begin{array}{l}\text { Rekan kerja saya apabila saya mengalami kesulitan, ia } \\
\text { cepat tanggap untuk memantu saya }\end{array}$ & 4,30 & 86 & Baik \\
\hline 10 & $\begin{array}{l}\text { Saya merasa puas dengan kesempatan yang diberikan } \\
\text { dalam pengembangkan karir }\end{array}$ & 4.18 & 83,6 & Baik \\
\hline 11 & $\begin{array}{l}\text { Saya diberikan kesempatan untuk menduduki posisi yang } \\
\text { berbeda dalam organisasi }\end{array}$ & 4,30 & 86 & Baik \\
\hline 12 & $\begin{array}{l}\text { Pengembangan karir dilaksanakan berdasar hasil kerja } \\
\text { dalam organisasi }\end{array}$ & 4,21 & 84,2 & Baik \\
\hline 13 & $\begin{array}{l}\text { Saya merasa puas apabila supervisor memuji hasil kerja } \\
\text { saya yang bagus }\end{array}$ & 4.29 & 85,8 & Baik \\
\hline 14 & Supervisor selalu mengikuti perkembangan saya & 4,30 & 86 & Baik \\
\hline 15 & $\begin{array}{l}\text { Pekerjaan tersebut sudah memberikan tantangan tersendiri } \\
\text { kepada saya }\end{array}$ & 4.43 & 88,6 & Baik \\
\hline 16 & $\begin{array}{l}\text { Saya berkesempatan untuk menggunakan metode sendiri } \\
\text { dalam menjalankan tugas }\end{array}$ & 4.29 & 85,8 & Baik \\
\hline & Rata - Rata & 4.24 & 84,8 & Baik \\
\hline
\end{tabular}

Tabel 2

Distribusi Frekuensi Variabel Kepuasan Kerja (Y) 
Berdasarkan uraian dari Tabel 2 menunjukkan bahwa skor rata-rata variabel Kepuasan Kerja adalah sebesar 4.24 dengan tingkat capaian responden (TCR) sebesar 84,8 $\%$. Hal ini menunjukkan bahwa Kepuasan Kerja masuk dalam kategori baik. Dengan demikian dapat disimpulkan bahwa Kepuasan Kerja guru kategori baik dalam menjalankan aktivitasnya sehari-hari sebagai pegawai. Jadi temuan penelitian ini membuktikan bahwa Kepuasan Kerja guru sudah baik. Untuk itu diharapkan bagi pihak sekolah agar dapat mempertahankan kepuasan kerja guru serta meningkatkatkannya lagi agar lebih baik kedepannya demi untuk kemajuan bangsa dan negara ini serta perlu perbaikan agar tujuan organisasi pun juga tercapai. Disamping itu para guru harus mampu memperbaiki cara kerja yang efektif dan efisien sesuai dengan standar yang ditetapkan dalam menyelesaikan alur pekerjaan secara tepat guna dan tepat waktu serta harus ada dukungan dari pimpinan / kepala sekolah.

\section{b. Hasil Uji Distribusi Frekuensi Variabel Kepemimpinan}

Tabel 3 Distribusi Frekuensi Variabel Kepemimpinan $\left(\mathbf{X}_{1}\right)$

\begin{tabular}{|c|c|c|c|c|}
\hline No & Pernyataan & Rata-rata & TCR & Ket \\
\hline 1 & $\begin{array}{l}\text { Pimpinan menghadapi tantangan tugas dengan tetap mampu } \\
\text { memelihara suasana kerja yang menyenangkan }\end{array}$ & 4.21 & 84,2 & Baik \\
\hline 2 & $\begin{array}{l}\text { Dorongan pimpinan kepada para pegawai untuk terus belajar bagi } \\
\text { peningkatkan kapasitas organisasi }\end{array}$ & 4.05 & 81 & Baik \\
\hline 3 & Adanya ketegasan pimpinan dalam pengambilan keputusan & 4.29 & 85,8 & Baik \\
\hline 4 & Pimpinan memiliki pandangan jauh kedepan & 4.39 & 87,8 & Baik \\
\hline 5 & $\begin{array}{l}\text { Pimpinan mengajak para para pegawai untuk bersama-sama } \\
\text { merumuskna tujuan }\end{array}$ & 4.30 & 86 & Baik \\
\hline 6 & Visi dan misi disosialisasikan kepada seluruh pegawai & 4.23 & 84,6 & Baik \\
\hline 7 & $\begin{array}{l}\text { Pimpinan mengadakan pertemuan / rapat uuntuk membahas masalah } \\
\text { yang terjadi ditempat kerja }\end{array}$ & 4.18 & 83,6 & Baik \\
\hline 8 & $\begin{array}{l}\text { Pimpinan memberikan keterangan yang sesuai dengan tugas para } \\
\text { pegawai }\end{array}$ & 4.12 & 82,4 & Baik \\
\hline 9 & $\begin{array}{l}\text { Pimpinan meningkatkan gairah kerja dan membina tingkah laku } \\
\text { para pegawai yang produktif untuk pencapian target kerja }\end{array}$ & 4.18 & 83,6 & Baik \\
\hline 10 & $\begin{array}{l}\text { Pimpinan memberikan contoh teladan yang baik kepada para } \\
\text { pegawai }\end{array}$ & 4.11 & 82,2 & Baik \\
\hline 11 & $\begin{array}{l}\text { Pimpinan memberitahukan kepada para pegawai apa yang harus } \\
\text { dikerjakan dan bagaimana cara mengerjakannya }\end{array}$ & 4.00 & 80 & Baik \\
\hline 12 & $\begin{array}{l}\text { Kesalahan anak buah dalam tugas, dalam praktek sepenuhnya } \\
\text { adalah menjadi tanggung jawab pimpinan }\end{array}$ & 4.21 & 84,2 & Baik \\
\hline 13 & $\begin{array}{l}\text { Sikap dan perilaku pimpinan terhadap para pegawai memberikan } \\
\text { ransangan untuk membangkitkan gairah kerja }\end{array}$ & 4.21 & 84,2 & Baik \\
\hline 14 & $\begin{array}{l}\text { Pimpinan sangat simpati terhadap para pegawai dan memberikan } \\
\text { nasehat apabila terjadi kesalahan }\end{array}$ & 4.21 & 84,2 & Baik \\
\hline 15 & $\begin{array}{l}\text { Pimpinan memberikan perhatian dan menghargai para pegawai } \\
\text { sebagai pribadi manusia }\end{array}$ & 4.20 & 84 & Baik \\
\hline \multirow[t]{2}{*}{16} & $\begin{array}{l}\text { Pimpinan memberikan kesempatan kepada pegawai untuk } \\
\text { menyampaikan perasaan dan perhatiannya }\end{array}$ & 4.20 & 84 & Baik \\
\hline & Rata - Rata & 4,19 & $\mathbf{8 3 , 8}$ & Baik \\
\hline
\end{tabular}

Dari tabel 3 diatas, dapat diperoleh informasi bahwa skor rata-rata variabel kepemimpinan (X1) sebesar 4,19 dengan tingkat pencapaian responden 83,8\% hal ini menunjukkan bahwa variabel kepemimpinan masuk dalam kategori baik semoga kedepannya dapat ditingkatkan lagi dan keadaan yang ada sekarang ini dapat dipertahankan. 


\section{Hasil Analisis Regresi Linier Sederhana}

Hasil analisa regresi linear sederhana dapat dijelaskan pada Tabel 4 berikut:

Tabel 4 Hasil Analisis Regresi Linier Sederhana

Coefficients $^{\mathrm{a}}$

\begin{tabular}{|c|c|c|c|c|c|c|c|}
\hline & \multirow[t]{2}{*}{ Model } & \multicolumn{2}{|c|}{$\begin{array}{c}\text { Unstandardized } \\
\text { Coefficients } \\
\end{array}$} & \multirow{2}{*}{\multicolumn{2}{|c|}{$\begin{array}{c}\begin{array}{c}\text { Standardized } \\
\text { Coefficients }\end{array} \\
\text { Beta }\end{array}$}} & \multirow[t]{2}{*}{$\mathbf{t}$} & \multirow[t]{2}{*}{ Sig. } \\
\hline & & B & Std. Error & & & & \\
\hline \multirow[t]{2}{*}{1} & (Constant) & 28.173 & 6.082 & & & 4.632 & .000 \\
\hline & $\begin{array}{l}\text { kepemimpina } \\
\mathrm{n}\end{array}$ & .530 & .090 & & .624 & 5.865 & .000 \\
\hline
\end{tabular}

a. Dependent Variable: Kepuasan_kerja

Pada tabel tersebut menunjukkan bahwa persamaan regresi adalah sebagai berikut:

$$
\mathrm{Y}=28,173+0,530 \mathrm{X}_{1}
$$

Dari persamaan tersebut dapat dijelaskan bahwa:

1. Nilai konstanta sebesar 28,173 , hal ini menunjukkan bahwa sebelum dipengaruhi kepemimpinan sebagai variabel independen, maka nilai kepuasan kerja guru sebesar 28,173 dengan asumsi variabel lainya tetap.

2. Koefisien Kepemimpinan memberikan nilai sebesar 0,530, yang berarti bahwa jika kepemimpinan ditingkatkan satu satuan maka kepuasan kerja guru akan

\section{Uji Hipotesa} meningkat sebesar 0,530 dengan asumsi variabel lain tetap.

\section{a. Uji Parsial (Uji t) \\ Hasil Uji Parsial (Uji t)}

Tabel 5

Pengujian Secara Parsial Atas Semua Variabel Independen

\begin{tabular}{|c|r|r|}
\hline Faktor Independent & \multicolumn{1}{|c|}{ t } & \multicolumn{1}{|c|}{ Sig. } \\
\hline (Constant) & 4.632 & .000 \\
Kepemimpinan & 5.865 & .000 \\
\hline
\end{tabular}

Berdasarkan perhitungan pada Tabel 5 diatas terlihat bahwa hasil uji secara parsial variabel kepemimpinan $(\mathrm{X})$ berpengaruh positif dan signifikan terhadap kepuasan kerja guru. Nilai t dari kepemimpinan $\left(X_{1}\right)$ adalah sebesar 5,865, nilai signifikansinya adalah 0,000. Apabila nilai signifikansi lebih kecil dari tingkat signifikan yang digunakan $(0,000<0,05)$. Hal ini berarti bahwa hipotesa yang di ajukan dapat diterima dengan tingkat kebenaran $95 \%$.

Jadi dapat disimpulkan bahwa semakin baik kepemimpinan seorang kepala sekolah maka kepuasan kerja juga akan semakin meningkat, untuk itu diharapkan kepala sekolah dapat mengayomi semua yang terlibat dalam kegiatan organisasi tanpa ada membeda-bedakan mereka.

Penelitian ini juga didukung atau diperkuat oleh Sudharto (2011:462) menyatakan bahwa kepemimpinan berpengaruh posirif dan signifikan terhadap kepuasan kerja guru.

\section{b. Uji Simultan (Uji f)}

Analisis secara bersama - sama menunjukkan terdapat pengaruh yang positif dan signifikan antara Kepemimpinan terhadapa Kepuasan Kerja Guru pada SMPN 1 Banuhampu Kabupaten Agam. Seperti yang disajikan pada tabel berikut : 
Tabel 6 Hasil Uji F Simultan ANOVA $^{\mathrm{b}}$

\begin{tabular}{|ll|r|r|r|r|r|}
\hline \multicolumn{1}{|c|}{ Model } & Sum of Squares & Df & Mean Square & F & Sig. \\
\hline 1 & Regression & 450.201 & 1 & 450.201 & 34.397 & $.000^{2}$ \\
Residual & 706.782 & 54 & 13.089 & & \\
Total & 1156.982 & 55 & & & \\
\hline
\end{tabular}

a. Predictors: (Constant), kepemimpinan

b. Dependent Variable: Kepuasan_kerja

Dari tabel diatas menunjukkan bahwa nilai signifikansinya adalah 0,000 dan F hitung 34,397. ini berarti bahwa model regresi dapat digunakan untuk memprediksi kepuasan kerja guru karena nilai signifikansinya $<$ dari 0,05 sehingga hipotesa yang di ajukan secara bersama sama dapat diterima dengan tingkat kebenaran $95 \%$.

\section{Kesimpulan}

Setelah dilakukan berbagai pembahasan mengenai pengaruh kepemimpinan terhadap kepuasan kerja guru pada SMPN 1 Banuhampu Kabupaten Agam, maka dapat ditarik kesimpulan sebagai berikut:

1. Secara simultan kepemimpinan berpengaruh positif dan signifikan terhadap kepuasan kerja guru. Dengan kata lain bahwa kepuasan kerja guru pada SMPN 1 Banuhampu dipengaruhi oleh kepemimpinan. Kontribusi pengaruh variabel diatas (X) diperoleh kesesuaian dengan koefisien determinasin $37,8 \%$ sedangkan sisanya sebesar $62,2 \%$ dipengaruhi oleh variabel lain yang tidak diteliti dalam kesempatan ini.

2. Secara parsial kepemimpinan berpengaruh positif dan signifikan terhadap Kepuasan Kerja Guru. Dengan peningkatan Kepemimpinan akan menjadikan Guru lebih bertanggung jawab, disiplin dalam melaksanakan tugas yang dibebankan kepadanya, maka hipotesa dapat diterima.

\section{DAFTAR PUSTAKA}

Edy Sutrisno. 2009. Manajemen Sumber Daya Manusia, Edisi Pertama, Cetakan Pertama, Jakarta: Prenada Media

Ghozali, Imam. 2013. Aplikasi Analisis Multivariate dengan Program IBM SPSS 21 Update PLS Regresi. Semarang: Badan Penerbit Universitas Diponegoro Volume 3. Nomor 1

Koesmono, Teman. 2005. Pengaruh Kempemimpinan, Motivasi, Pelatihan dan Lingkungan Kerja pada kinerja Karyawan Pada Perusahaan Daerah Air Minum Kota Surakarta. Volume XVII. Nomor 1. April. Hal. 79 - 92. STIE YKPN. Yogyakarta.

Kouzes, James M \& Posner, Barry Z. 2004. leadership the challenge (Tantangan Kepemimpinan, Edisi Ketiga. Jakarta : Penerbit Erlangga.

Munandar. 2004. Manajemen Sumber Daya Manusia. Erlangga : Jakarta.

Pandji Anoraga. 2007 . Manajemen Bisnis. cetakan ketiga, Jakarta: Rineka Cipta

Rivai, Veithzal. 2009. Manajemen Sumber Daya Manusia,Jakarta cetakan kesembilan

Robbins, P. Stephen. 2003. Perilaku Organisasi. Edisi Sembilan, Jilid 2. Edisi Bahasa Indonesia. PT Indeks Kelompok Gramedia, Jakarta

Sanusi, Ahmad. 2009. Kepemimpinan Sekarang Dan Masa Depan. Bandung: Prospect

Siagian Sondang P., 2002. Kiat Meningkatkan Produktivitas Kerja, Cetakan Pertama, PT. Rineka Cipta, Jakarta.

Sudharto, 2011. Pengaruh Kepemimpinan Kepala Sekolah dan Kompensasi Terhadap Kepuasan Keraj Guru SMPN Kota Semarang. Cakrawala Pendidikan, November 2011, Th. XXX, No. 3 